\title{
RT-PCR amplification and sequence analysis of extra small virus associated with white tail disease of Macrobrachium rosenbergii (de Man) cultured in Taiwan
}

\author{
C S Wang ${ }^{1}$, J S Chang ${ }^{1}$, H H Shih ${ }^{2}$ and S N Chen ${ }^{3}$ \\ 1 Department of Life Science, National University of Kaohsiung, Kaohsiung, Taiwan \\ 2 Department of Life Science, National Taiwan University, Taipei, Taiwan \\ 3 Institute of Fisheries Science, National Taiwan University, Taipei, Taiwan
}

\begin{abstract}
Post-larvae of Macrobrachium rosenbergii infected with white tail disease (WTD) have been reported in Taiwan. The causative agents have been identified as $M$. rosenbergii nodavirus $(M r \mathrm{NV})$ associated with extra small virus (XSV). The present study is the first report confirming the presence of XSV virus in $M$. rosenbergii displaying WTD symptoms in Taiwan by reverse transcription polymerase chain reaction (RT-PCR). A $772 \mathrm{bp}$ amplified product was obtained by RT-PCR, cloned and sequenced. The nucleotide sequence analysis of the $772 \mathrm{bp}$ DNA fragment revealed $98 \%$ and $97 \%$ identity with XSV isolated from China and India, respectively. Comparison of the deduced amino acid sequences of the XSV partial genome showed strong homology (99\% and 97\%) with isolates from China and India. Phylogenetic analysis revealed the XSV-Taiwan isolate was more closely related to the Chinese rather than the Indian isolates. The results demonstrated the presence of XSV virus co-infection in $M$. rosenbergii cultured in Taiwan suffering from WTD.
\end{abstract}

Keywords: Macrobrachium rosenbergii, RT-PCR, sequence analysis, white tail disease, XSV.

\section{Introduction}

The giant freshwater prawn, Macrobrachium rosenbergii (de Man), is an economically important

Correspondence Dr C S Wang, Department of Life Science, National University of Kaohsiung, Kaohsiung 811, Taiwan

(C) 2007 The Authors Journal compilation (C) 2007

Blackwell Publishing Ltd palaemonid in Taiwan. An epizootic disease designated as white tail disease (WTD) has been observed in hatcheries and nursery ponds since 1992. This disease has caused high mortalities and huge economic losses (Tung, Wang \& Chen 1999). WTD has recently been reported in China (Qian, Shi, Zhang, Cao, Liu, Li, Xie, Cambournac \& Bonami 2003), India (Sahul Hameed, Yoganandhan, Sri Widada \& Bonami 2004a; Shekhar, Azad \& Jithendran 2006), Thailand (Yoganandhan, Leartvibhan, Sriwongpuk \& Limsuwan 2006) and the French West Indies (Arcier, Herman, Lightner, Redman, Mari \& Bonami 1999). The affected prawns exhibit white opaque muscle in abdominal segments, commonly accompanied by progressive weakening of their feeding and swimming ability. The mortalities reached between $50 \%$ and $70 \%$ after transferring the post-larvae (PL) to the growout ponds (Tung et al. 1999).

The causative agents of WTD have been identified as $M$. rosenbergii nodavirus $(M r \mathrm{NV})$ associated with extra small virus (XSV) (Qian et al. 2003). M. rosenbergii nodavirus is a small icosahedral non-enveloped virus, $26-27 \mathrm{~nm}$ in diameter, observed in the cytoplasm of connective tissue cells in infected prawns. The viral genome is formed by two pieces of single-stranded, positive-sense RNA (RNA1 and RNA2), of about 2.9 and $1.3 \mathrm{~kb}$ in length, respectively. The viral capsid contains a single polypeptide of $43 \mathrm{kDa}$ (Bonami, Shi, Qian \& Sri Widada 2005). The XSV virus is icosahedral in shape, $15 \mathrm{~nm}$ in diameter. The genome consists of a linear single-stranded RNA of 796 nucleotides, encoding a single structural protein of $17 \mathrm{kDa}$ 
(CP-17) (Sri Widada \& Bonami 2004). Because the clinical signs exhibited are not specific to WTD, other methods are required to screen for the aetiological agent. A number of diagnostic methods have been developed for detecting $M r \mathrm{NV}$, including dot-blot hybridization, in situ hybridization, reverse transcription polymerase chain reaction (RT-PCR) and ELISA (Sri Widada, Durand, Cambournac, Qian, Shi, Dejonghe, Richard \& Bonami 2003; Romestand \& Bonami 2003). Dot blot hybridization and RT-PCR have also been developed for detection of XSV (Sri Widada, Richard, Shi, Qian \& Bonami 2004). A singletube, one-step multiplex RT-PCR has been developed for detecting $M r \mathrm{NV}$ and XSV (Yoganandhan, Sri Widada, Bonami \& Sahul Hameed 2005).

Although the relationships between $M r \mathrm{NV}$ and $\mathrm{XSV}$ virus remains unknown, it is hypothesized that XSV constitutes a new species of satellite virus (Sri Widada \& Bonami 2004). Similar clinical signs associated with $M r \mathrm{NV}$ virus infection were reported in diseased M. rosenbergii from Taiwan (Tung et al. 1999) but the phenomenon of co-infection with the satellite virus was not demonstrated in WTDinfected prawns. The present study is the first report confirming the presence of XSV virus in WTD affected $M$. rosenbergii in Taiwan by RT-PCR. Furthermore, the RT-PCR amplified product of XSV virus was cloned and sequenced, and the phylogenetic relationships between different geographic isolates were investigated.

\section{Materials and methods}

\section{Collection of infected post-larvae}

Infected PL (24-32 days of age) of $M$. rosenbergii with WTD were collected from affected hatcheries located in Kaohsiung and Pington in southern Taiwan. More than 30 samples of diseased giant freshwater prawns, each consisting of 10-30 individuals were collected from the WTD-affected hatcheries. Healthy animals were obtained from a different hatchery with no record of WTD, and the absence of the disease was further confirmed by histological analysis. The PL were washed in sterile distilled water and stored at $-20{ }^{\circ} \mathrm{C}$ before processing.

\section{Total RNA extraction}

(C) 2007 The Authors. Journal compilation (C) 2007 Blackwell Publishing Ltd
Total RNA was extracted using TRIzol ${ }^{\mathrm{TM}}$ reagent (Invitrogen, Carsbad, CA, USA) following the manufacturer's protocol. Briefly, $30-50 \mathrm{mg}$ of muscle from 3-5 PL was homogenized in $950 \mu \mathrm{L}$ TRIzol $^{\mathrm{TM}}$ reagent by power homogenizer. The homogenates were incubated for $5 \mathrm{~min}$ at room temperature, and then $0.2 \mathrm{~mL}$ chloroform was added. The samples were vigorously shaken for 2 $3 \mathrm{~min}$, and then centrifuged at $12000 \mathrm{~g}$ for $15 \mathrm{~min}$ at $4{ }^{\circ} \mathrm{C}$. The aqueous phase from the tube was transferred to a fresh tube. Total RNA was precipitated from the aqueous phase with isopropanol, washed with $75 \%$ ethanol and dissolved in $50 \mu \mathrm{L}$ diethyl pyrocaronate-treated water and stored at $-70{ }^{\circ} \mathrm{C}$.

\section{RT-PCR for XSV}

Reverse transcription polymerase chain reaction was performed using a Reverse-i $\mathrm{T}^{\mathrm{TM}}$ one-step RT-PCR kit (ABgene, Surrey, UK), allowing RT and amplification to be carried out in a single reaction tube. The upstream primer XSV-1 5'-CCACGTCTAGCTGCTGAC- $3^{\prime}$ and the downstream primer XSV-772 5'-CGGAATAATGCCTAACCAAT-3' specific to XSV were designed from sequence data of GenBank accession no.AY247793. The size of the amplified product was $772 \mathrm{bp}$. The reaction was performed in $50 \mu \mathrm{L}$ RT-PCR buffer containing 10 pmol of each primer and RNA template, using the following steps: RT at $55^{\circ} \mathrm{C}$ for $1 \mathrm{~h}$; denaturation at $94^{\circ} \mathrm{C}$ for 2 min followed by 35 cycles of denaturation at $94{ }^{\circ} \mathrm{C}$ for $40 \mathrm{~s}$; annealing at $52^{\circ} \mathrm{C}$ for $40 \mathrm{~s}$ and elongation at $72^{\circ} \mathrm{C}$ for $1 \mathrm{~min}$, ending with an additional elongation step of $10 \mathrm{~min}$ at $72{ }^{\circ} \mathrm{C}$. The amplified product was analysed by electrophoresis on a $1.5 \%$ agarose gel.

\section{Cloning and sequence analysis}

The RT-PCR products were extracted from agarose gel, and purified using a PCR clean-up system (Promega, Madison, WI, USA). The DNA fragments were ligated into pGEM-T easy vector (Promega) and transformed into Escherichia coli DH-5a. The recombinant plasmid DNA was extracted, and automatic sequencing was performed commercially (Protech Technology Enterprise Co., Ltd, Taipei, Taiwan). Sequence analysis was done with other XSV isolates recorded at GenBank (GenBank accession no.DQ174318 for a Chinese strain and GenBank accession no.AY247793 for an Indian strain) using BLAST (Altschul, Madden, Schäffer, Zhang, Zhang,

Miller \& Lipman 1997) and Clustal W (Thompson, 
Higgins \& Gibson 1994). The phylogenetic analysis was performed using the neighbour-joining method (Saitou \& Nei 1987).

\section{Results}

The diseased post-larvae with whitish muscle were collected from different hatcheries located in

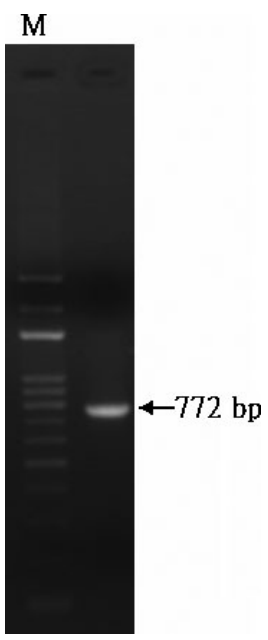

Figure 1 Agarose gel showing RT-PCR products of extra small virus extracted from post-larvae of white tail disease-infected prawn. M: 100 bp DNA ladder marker. southern Taiwan. The clinical sign of infected PL was non-transparent muscle in abdominal segments. All 30 WTD affected cases were shown to be infected with XSV virus infection by RT-PCR analysis. However, the samples obtained from the unaffected hatchery were negative for the presence of XSV. As shown in Fig. 1, the 772 bp products were obtained using the primer pair (XSV-1/XSV772) specific to the genome of XSV virus. The RTPCR products were purified and cloned into pGEM-T plasmid, and then sequenced. The nucleotide sequence and deduced amino acid of XSV partial genome are shown in Fig. 2 (GenBank accession no.DQ521573). It contained a unique open reading frame with 522 nucleotides and could encode a structural protein with 174 amino acids. Comparisons by Clustal W analysis revealed that the nucleotide sequence of the XSV Taiwan isolate was very similar to those of XSV isolates from China and India (Fig. 3). BLAST analysis revealed $98 \%$ and $97 \%$ identity of nucleotide sequence of XSV with isolates from China and India, respectively. In addition, the deduced amino acid sequence of the XSV Taiwan isolate showed strong homology with Chinese and Indian isolates. Only one deduced amino acid substitution at position 139 $(\mathrm{I} \rightarrow \mathrm{M})$ was observed which differed from the
(C) 2007 The Authors Journal compilation (C) 2007

Blackwell Publishing Ltd
Figure 2 Nucleotide sequence and deduced amino acid sequence of extra small virus (XSV) partial genome from Taiwan isolate (GenBank accession no. DQ521573). The numbering for the nucleotide sequences is given on the left and the numbering for the sequences of deduced amino acids is given on the right. ccacgtctagctgctgacgttaaatgcagccgggtggaaatgcgtattaatattttaac

aacatgaataagcgcattaataataatcggagaaccatgagatcacgtaggggacgtggt

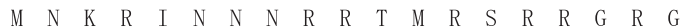

aggacaatgggatctaatctcattccttatgccaactcaccagtcctataccatataca $\begin{array}{llllllllllllllllllll}R & T & M & G & S & N & L & I & P & Y & A & N & S & P & V & P & \text { I } & P & Y & T\end{array}$

ccaccottacccagttaccgtcattggtaatcctcggaaactacttggattgacatt

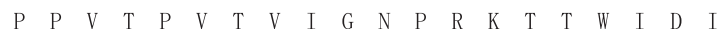
gatctttcaagtgaagagtccgggatttacactttgacggttgggtcataccgtaatagg $\begin{array}{llllllllllllllllllll}\text { D } & \text { L } & S & S & E & E & S & G & I & Y & T & L & T & V & G & S & Y & R & N & R\end{array}$ attactaaacttggtccatctaaacctaactttattattgagaaggtcgcagcatatgct $\begin{array}{llllllllllllllllllll}\text { I } & \text { T } & \text { K } & \text { L } & G & \text { P } & \text { S } & \text { K } & \text { P } & \text { N } & \text { F } & \text { I } & \text { I } & \text { E } & \text { K } & \text { V } & \text { A } & \text { A } & \text { Y } & \text { A }\end{array}$ gcaccaggagattataaggttgttctcaatgactttaaaactggtatacaagtcgttgat

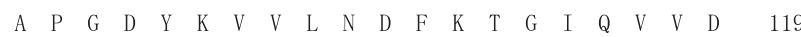
gaaggctcttatgctcatagagccgcagcaggtattcttatccacctgctgcacaaatg $\begin{array}{llllllllllllllllllll}\text { E } & G & \text { S } & \text { Y } & \text { A } & \text { H } & \text { R } & \text { A } & \text { A } & \text { A } & \text { G } & \text { I } & \text { L } & \text { Y } & \text { P } & \text { P } & \text { A } & \text { A } & \text { Q } & \text { M }\end{array}$ ttttacggtatttcagcaacaggcacactcaacactattactaccactgctaaagatcca

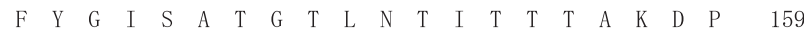
gttccagtggttcgtgctttggtaacatattgggactccgaacagtaatgagcaggttct

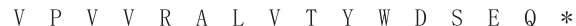




\begin{tabular}{|c|c|c|}
\hline XSV-Tw & ----------_CCACGTCTAGCTGCTGACGTTAAATGCAGCCGGG & 34 \\
\hline China-DQ174318 & TTGTAAAACAAGCTTCGGCTTGTTTTACACGTCTAGCTGCTGACGTTAAATGCAGCCGGG & 60 \\
\hline \multirow[t]{2}{*}{ India-AY247793 } & -_-_-_-_-_CACGTCTAGCTGCTGACGTTAAATGCAGCCGGG & 34 \\
\hline & $* * * * * * * * * * * * * * * * * * * * * * * * * * * * * * * * * *$ & \\
\hline XSV-Tw & TGGAAATGCGTATTAATATTTTAACAACATGAATAAGCGCATTAATAATAATCGGAGAAC & 94 \\
\hline China-DQ174318 & TGGTAATGCGTATTAATATTTCAACAACATGAATAAGCGCATTAATAATAATCGGAGAAC & 120 \\
\hline \multirow[t]{2}{*}{ India-AY247793 } & TGGTAATGCGTATTAATATTTCAACAACATGAATAAGCGCATTAATAATAATCGGAGAAC & 94 \\
\hline & *** $* * * * * * * * * * * * * * * * * * * * * * * * * * * * * * * * * * * * * * * * * * * * * * * * * * * * * * * * * *$ & \\
\hline XSV-Tw & CATGAGATCACGTAGGGGACGTGGTAGGACAATGGGATCTAATCTCATTCCTTATGCCAA & 154 \\
\hline China-DQ174318 & CATGAGATCACGTAGGGGACGTGGTAGGACAATGGGATCTAATCTCATTCCTTATGCCAA & 180 \\
\hline \multirow[t]{2}{*}{ India-AY247793 } & CATGAGATCACGTAGGGGACGCGGTAGGACAATGGGATCTAATCTCATTCCTTACGCCAA & 154 \\
\hline & 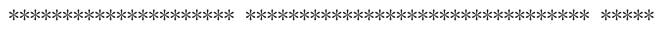 & \\
\hline XSV-Tw & CTCACCAGTCCCTATACCATATACACCACCCGTTACCCCAGTTACCGTCATTGGTAATCC & 214 \\
\hline China-DQ174318 & CTCACCAGTCCCTATACCATATACACCACCCGTTACCCCAGTCACCGTCATTGGTAATCC & 240 \\
\hline India-AY247793 & $\begin{array}{l}\text { TTCACCAGTCCCTATACCATATACACCACCCGTTACCCCAGTCACCGTCATTAGTAATCC } \\
\text { T* }\end{array}$ & 214 \\
\hline XSV-Tw & TCGGAAAACTACTTGGATTGACATTGATCTTTCAAGTGAAGAGTCCGGGATTTACACTTT & 274 \\
\hline China-DQ174318 & TCGGAAAACTACTTGGATTGACATTGATCTTTCAAGTGAAGAGTCCGGGATTTACACATT & 300 \\
\hline \multirow[t]{2}{*}{ India-AY247793 } & TCGGAAAACTACTTGGATTGACATTGATCTTTCAAGTGAAGAGTCCGGGATTTACACATT & 274 \\
\hline & *************************************************************** $* *$ & \\
\hline XSV-Tw & GACGGTTGGGTCATACCGTAATAGGATTACTAAACTTGGTCCATCTAAACCTAACTTTAT & 334 \\
\hline China-DQ174318 & GACGGTTGGGTCATACCGTAATAGGATCACTAAACTTGGTCCATCTAAACCTAACTTTAT & 360 \\
\hline \multirow[t]{2}{*}{ India-AY247793 } & GGCGGTTGGGTCATACCGTAATAGGATTACTAAACTTGGTCCATCTAAACCTAACTTTAT & 334 \\
\hline & $* * * * * * * * * * * * * * * * * * * * * * * * * * * \quad * * * * * * * * * * * * * * * * * * * * * * * * * * * * * * * * * *$ & \\
\hline XSV-Tw & TATTGAGAAGGTCGCAGCATATGCTGCACCAGGAGATTATAAGGTTGTTCTCAATGACTT & 394 \\
\hline China-DQ174318 & TATTGAGAAGGTCGCAGCATATGCTGCACCAGGAGATTATAAGGTTGTTCTCAATGACTT & 420 \\
\hline \multirow[t]{2}{*}{ India-AY247793 } & TATTGAGAAGGTTGCAGCATACGCTGCACCAGGAGATTATAAGGTTGTTCTCAATGACTT & 394 \\
\hline & $* * * * * * * * * * * * * * * * * * * * * * * * * * * * * * * * * * * * * * * * * * * * * * * * * * * * * * * * * * * * * * * *$ & \\
\hline XSV-Tw & TAAAACTGGTATACAAGTCGTTGATGAAGGCTCTTATGCTCATAGAGCCGCAGCAGGTAT & 454 \\
\hline China-DQ174318 & TAAAACTGGTATACAAGTCGTTGATGAAGGCTCTTATGCTCATAGAGCCGCAGCAGGTAT & 480 \\
\hline \multirow[t]{2}{*}{ India-AY247793 } & TAAAACTGGCATACAAGTCGTTGATGAAGGCTCTTATGCTCATAGAGCCGCAGTAGGTAT & 454 \\
\hline & $* * * * * * * * * \quad * * * * * * * * * * * * * * * * * * * * * * * * * * * * * * * * * * * * * * * * * * * * * * *) * * * * * *$ & \\
\hline XSV-Tw & TCTTTATCCACCTGCTGCACAAATGTTTTACGGTATTTCAGCAACAGGCACACTCAACAC & 514 \\
\hline China-DQ174318 & TCTTTATCCACCAGCTGCACAAATATTTTACGGTATTTCAGCAACAGGCACACTCAACAC & 540 \\
\hline \multirow[t]{2}{*}{ India-AY247793 } & TCTTTATCCACCTGCTGCACAAATATTTTACGGTATTTCAGCAACAGGCACACTCAATAC & 514 \\
\hline & $* * * * * * * * * * * * \quad * * * * * * * * * * * * * * * * * * * * * * * * * * * * * * * * * * * * * * * * * * * * * *) \quad * *$ & \\
\hline $\mathrm{XSV}-\mathrm{Tw}$ & TATTACTACCACTGCTAAAGATCCAGTTCCAGTGGTTCGTGCTTTGGTAACATATTGGGA & 574 \\
\hline China-DQ174318 & TATCACTACCACTGCTAAAGATCCAGTTCCAGTGGTTCGTGCTTTGGTAACATATTGGGA & 600 \\
\hline \multirow[t]{2}{*}{ India-AY247793 } & TATCACTACCACTGCTAAAGATCCAGTTCCAGTGGTTCGTGCCTTGGTAACATATTGGGA & 574 \\
\hline & *** $* * * * * * * * * * * * * * * * * * * * * * * * * * * * * * * * * * * * * * * * \quad * * * * * * * * * * * * * * * * * *$ & \\
\hline XSV-Tw & CTCCGAACAGTAATGAGCAGGTTCTATGCTTCGAACTAAAACAAGCAATGAGTTCTAGCT & 634 \\
\hline China-DQ174318 & CTCCGAACAGTAATGAGCAGGTTCTATGCTTCGAACTAAAACAAGCAATGAGTTCTAGCT & 660 \\
\hline \multirow[t]{2}{*}{ India-AY247793 } & CTCCGAACAGTAATGAGCAGGTTCTATGCTTCGAACTAAAACAAGCAATGAGTTCTAGCT & 634 \\
\hline & ************************************************************************* & \\
\hline XSV-Tw & CCGAACTAAAACGAGCCAAACTCTCGCATCTGAGTATAAATCATGCCCCATGATCCTCGC & 694 \\
\hline China-DQ174318 & CCGAACTAAAACGAGCCACACTCTCGCATCTGAGTATAAATCATGCCCCATGATCCTCGC & 720 \\
\hline \multirow[t]{2}{*}{ India-AY247793 } & CCGAACTAAAACGAGCCAAACTCTCGCATCTGAGTATAAATCATGCCCCATGATCCTCGC & 694 \\
\hline & $* * * * * * * * * * * * * * * * * * * \quad * * * * * * * * * * * * * * * * * * * * * * * * * * * * * * * * * * * * * * * * * * * * * * *$ & \\
\hline XSV-Tw & ATCGTATCGTACTTTGCTGGAGAAAACCCTTATGGCCAATTGTGGCAAGGGGAGACGTAT & 754 \\
\hline China-DQ174318 & ATCGTATCGCACTTTGCTGGAGAAAACCCTTACGGCCAATTGTGGCAAGGGGAGACGTAT & 780 \\
\hline \multirow[t]{2}{*}{ India-AY247793 } & ATCGTATCGCACTTTGCTGGAGAAAACCCTTATGGCCAATTGTGGCAAGGGGAGACGTAT & 754 \\
\hline & ********** $* * * * * * * * * * * * * * * * * * * * * * * * * * * * * * * * * * * * * * * * * * * * * * * * * * * * * *$ & \\
\hline XSV-Tw & TGGTTAGGCATTATTCCG-- & 772 \\
\hline China-DQ174318 & TGGTTAGGCATTATTCCGGGTGCGTCGATAAATAAAGACCTTAAAATATCCAAACAATTA & 840 \\
\hline \multirow[t]{2}{*}{ India-AY247793 } & TGGTTAGGCATTATTCCGGGTGCGTCGATAAATAAAGACCTT----------------- & 796 \\
\hline & $* * * * * * * * * * * * * * * * * *$ & \\
\hline XSV-Tw & & \\
\hline China-DQ174318 & GTTCTCATGGTGGATTTACACATTGACGGTTG 872 & \\
\hline India-AY247793 & & \\
\hline
\end{tabular}

(C) 2007 The Authors. Journal compilation (C) 2007 Blackwell Publishing Ltd

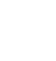

Figure 3 Multiple nucleotide sequence alignment of extra small virus (XSV) partial genome (XSV-Tw = XSV Taiwan isolate) with other geographical XSV isolates (China, GenBank accession no. DQ174318 and India, GenBank accession no. AY247793) using Clustal W. The degree of similarity is illustrated underneath the alignments with a series of consensus symbols. '*' Represents residues in that column identical in all sequences in the alignment. 


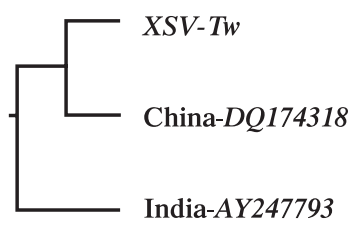

Figure 4 Phylogenetic neighbour-joining tree deduced from analysis nucleotide sequences of partial genome of extra small virus from different geographical isolates.

Chinese isolate. However, there were four changes at positions $49(\mathrm{~S} \rightarrow \mathrm{G}), \quad 72(\mathrm{~A} \rightarrow \mathrm{T}), \quad 129$ $(\mathrm{V} \rightarrow \mathrm{A})$ and $139(\mathrm{I} \rightarrow \mathrm{M})$ which occurred in XSV-Taiwan in contrast to the Indian isolate. The nucleotide sequences were used to construct a phylogenetic tree to examine the relationships between the three isolates. The results revealed the XSV-Taiwan isolate was more closely related to the Chinese than the Indian isolate (Fig. 4).

\section{Discussion}

The occurrence of WTD in $M$. rosenbergii has previously been reported in Taiwan (Tung et al. 1999). That histopathological study revealed dense viral inclusion bodies in the affected muscle of diseased prawns. Furthermore, non-enveloped virions with a mean size of $23 \mathrm{~nm}$ were observed in the cytoplasm of infected cells in the infected prawns, and were tentatively named as Macrobrachium muscle virus (MMV). However, the genomic characters of MMV were not evaluated, and coinfection with the satellite virus was not demonstrated. The present study confirmed XSV infection associated with WTD of $M$. rosenbergii cultured in Taiwan by RT-PCR.

Reverse transcription-polymerase chain reaction is considered the most sensitive method for detecting $M r \mathrm{NV}$ and XSV (Sri Widada et al. 2003). Using RT-PCR, it has been found that WTD samples from India are positive for XSV only (Sahul Hameed, Yoganandhan, Sri Widada \& Bonami 2004b), but another report from Thailand recorded only $M r \mathrm{NV}$ infection. It is hypothesized that failure to detect the dual infections was because single-step RT-PCR protocols were used (Yoganandhan et al. 2006). However, both $M r \mathrm{NV}$ and XSV were present together in all positive samples in our study (data not shown). These apparently contradictory results may be because different RT-PCR reaction conditions for XSV were used. For example, the number of cycles, annealing temperatures and the primer pair for RT-PCR used in our study differed from the previous reports. The role of the two viruses in the development of WTD is unknown. Although it is hypothesized that XSV constitutes a new species of satellite virus, the pathogenicity of this virus and its relationship to WTD merits further study.

In the present study, a primer pair specific to XSV was designed based on sequence data of XSV isolated from India (GenBank accession no. AY247793). Using this primer pair (XSV-1/XSV772 ), the 772 bp amplicon was successfully produced by RT-PCR. Sequence analysis of the partial genome demonstrated it contained 522 nucleotides that could encode a single structural protein with 174 amino acids. The results are similar to the previous reports from China and India. The deduced amino acid sequence of a 490-bp DNA fragment (GenBank accession no. DQ189991) of Thai XSV showed 100\% identity to Indian isolates (Yoganandhan et al. 2006). Furthermore, only one and four deduced amino acid substitutions were observed when compared with the isolates from China and India, respectively. The conserved sequences observed from different geographical regions indicate that XSV isolates are closely related. A phylogenetic tree of the nucleotide sequences of XSV also demonstrated the close relationships between these isolates. The results suggest that geographical proximity of the areas from which isolates were obtained may influence their identity.

Based on a previous study, XSV possesses the characteristics of satellite viruses such as those described in the plant kingdom (Sri Widada \& Bonami 2004). For example, the XSV genome only encodes structural protein CP-17, but does not possess the gene coding for viral RNA polymerase. It is hypothesized that XSV may depend on the RNA-dependent RNA polymerase of $M r \mathrm{NV}$ for its replication. However, comparison of the deduced amino acid sequences of CP-17 of XSV with known structural proteins of satellite viruses showed that XSV was not affiliated to known virus families. Further study is needed to investigate the real role of structural protein CP-17 of XSV in WTDinfected $M$. rosenbergii.

\section{References}

Altschul S.F., Madden T.L., Schäffer A.A., Zhang J., Zhang Z., Miller W. \& Lipman D.J. (1997) Gapped BLAST and PSIBLAST: a new generation of protein database search programs. Nucleic Acids Research 25, 3389-3402.
(C) 2007 The Authors Journal compilation (C) 2007 Blackwell Publishing Ltd 
Arcier J.M., Herman F., Lightner D.V., Redman R.M., Mari J. \& Bonami J.R. (1999) A viral disease associated with mortalities in hatchery-reared postlarve of the giant freshwater prawn Macrobrachium rosenbergii. Diseases of Aquatic Organisms 38, 177-181.

Bonami J.R., Shi Z., Qian D. \& Sri Widada J. (2005) White tail disease of the giant freshwater prawn, Macrobrachium rosenbergii: separation of the associated virions and characterization of $M r \mathrm{NV}$ as a new type of nodavirus. Journal of Fish Diseases 28, 23-31.

Qian D., Shi Z., Zhang S., Cao Z., Liu W., Li L., Xie Y., Cambournac I. \& Bonami J.R. (2003) Extra small virus-like particles (XSV) and nodavirus associated with whitish muscle disease in the giant freshwater prawn, Macrobrachium rosenbergii. Journal of Fish Diseases 26, 521-527.

Romestand B. \& Bonami J.R. (2003) A sandwich enzyme linked immunosorbent assay (S-ELISA) for detection of $M r \mathrm{NV}$ in the giant freshwater prawn, Macrobrachium rosenbergii (de Man). Journal of Fish Diseases 26, 71-75.

Sahul Hameed A.S., Yoganandhan K., Sri Widada J. \& Bonami J.R. (2004a) Studies on the occurrence of Macrobrachium rosenbergii nodavirus and extra small virus-like particles associated with white tail disease of $M$. rosenbergii in India by RT-PCR detection. Aquaculture 238, 127-133.

Sahul Hameed A.S., Yoganandhan K., Sri Widada J. \& Bonami J.R. (2004b) Experimental transmission and tissue tropism of Macrobrachium rosenbergii nodavirus $(\mathrm{MrNV})$ and its associated extra small virus (XSV). Diseases of Aquatic Organisms 62, 191-196.

Saitou N. \& Nei M. (1987) The neighbor-joining method: a new method for reconstructing phylogenetic trees. Molecular Biology and Evolution 4, 406-425.

Shekhar M.S., Azad I.S. \& Jithendran K.P. (2006) RT-PCR and sequence analysis of Macrobrachium rosenbergii nodavirus: Indian isolate. Aquaculture 252, 128-132.

Sri Widada J. \& Bonami J.R. (2004) Characteristics of the monocistronic genome of extra small virus, a virus-like particle associated with Macrobrachium rosenbergii nodavirus: possible candidate for a new species of satellite virus. Journal of General Virology 85, 643-646.

Sri Widada J., Durand S., Cambournac I., Qian D., Shi Z., Dejonghe E., Richard V. \& Bonami J.R. (2003) Genomebased detection methods of Macrobrachium rosenbergii nodavirus, a pathogen of the giant freshwater prawn, Macrobrachium rosenbergii: dot-blot, in situ hybridization and RTPCR. Journal of Fish Diseases 26, 583-590.

Sri Widada J., Richard V., Shi Z., Qian D. \& Bonami J.R. (2004) Dot-blot hybridization and RT-PCR detection of extra small virus (XSV) associated with white tail disease of prawn Macrobrachium rosenbergii. Diseases of Aquatic Organisms 58, 83-87.

Thompson J.D., Higgins D.G. \& Gibson T.J. (1994) CLUSTAL W: improving the sensitivity of progressive multiple sequence alignment through sequence weighting, positionspecific gap penalties and weight matrix choice. Nucleic Acids Research 22, 4673-4680.

Tung C.W., Wang C.S. \& Chen S.N. (1999) Histological and electron microscopic study on Macrobrachium muscle virus (MMV) infection in the giant freshwater prawn, Macrobrachium rosenbergii (de Man), cultured in Taiwan. Journal of Fish Diseases 22, 319-323.

Yoganandhan K., Sri Widada J., Bonami J.R. \& Sahul Hameed A.S. (2005) Simultaneous detection of Macrobrachium rosenbergii nodavirus and extra small virus by a single tube, onestep multiplex RT-PCR assay. Journal of Fish Diseases 28, 6569.

Yoganandhan K., Leartvibhan M., Sriwongpuk S. \& Limsuwan C. (2006) White tail disease of the giant freshwater prawn Macrobrachium rosenbergii in Thailand. Diseases of Aquatic Organisms 69, 255-258.

Received: 1 June 2006

Revision received: 11 August and 12 October 2006

Accepted: 16 October 2006
(C) 2007 The Authors Journal compilation (C) 2007 Blackwell Publishing Ltd 